\title{
A ENTOMOFTOROSE NASAL
}

\author{
Zilton A. Andrade * e Sonia G. Andrade **
}

Sâo apresentados os dados clinico-patológicos de dois casos de entomoftorose nasal, nova doença humana causada por um ficomiceto - Entomophthora ccronata. Os pacientes, uma menina e um homem, com 8 e 44 anos de idade respectivamente, apresentaram doença localizada, com nódulos no nariz e reoiāo paranasal, edema e deformaçāo da face. $O$ parasito foi isolado do primeiro caso, mas todas as tentativas para isolá-lo no segundo caso resultaram negativas. Histologicamente, havio reaçāo granulomatosa, fibrose e edema, em torno de hifas não septadas, as quais exibiam envólucro eosinófilo amorfo em torno. Foram demonstrados anticorpos circulantes contra as hifas do E. coronata no soro de um 'dos pacientes. O material eosinófilo em torno das hifas continha fibrina e material auto-fluorescente sob luz ultra-violeta, provavelmente lipofuscina, mas não foram demonstrados anticorpos ou antigenos nesta área.

A apresentação destes casos, os primeiros a serem descritos no Brasil, ë ucompanhada de uma revisão geral do assunto, pdis tal poderá vir a ser de interesse para aqueles que estudam os problemas do patologia tropical em nosso meio.

A entomoftorose nasal é uma nova doença humana causada por um ficomiceto denominado Entomophthora coronata (Delacroixia coronata). Em nosso Serviço foram diagnosticados dois casos desta rara micose, um dos quais já publicamos (2). Com o propósito de chamar a atenção dos colegas brasileiros para esta nova entidade, que tem características clínico-patoló gicas bem definidas, resolvemos aproveitar os dados colhidos durante o estudo dos dois referidos casos, especialmente no aue se refere à parte histopatológica, fazendo aqui uma revisão geral do assunto.

\section{SUMÁRIO CLÍNICO DOS CASOS}

$1^{\circ}$ Caso - Trata-se de menina de cor preta, com 8 anos, que se queixava de corrimento nasal, dores de cabeça e entumescimento dos tecidos em torno do nariz. Ao ser examinada, estava doente há um mês e apresentava edema bipalpebral bilateral e nódulos paranasais endurecidos, os quais faziam protusão nas cavidades nasais, causando obstruçāo parcial. Ao exame geral estava bem nutrida, sem sinais de doença geral. Foram feitos diversos exames complementares, sendo que a radiografia do

Trabaho do Serviço de Anatomia Patologica, Hospital Prof. Edgard Santos. Faculdade de Medicina da Universidade Federal da Bahia.

* Professor Adjunto.

* Professor Acsistente.

Recebido para publicaçá en 13.8 .72 
seio maxilar mostrou apenas espessamento da mucosa, sem envolvimento ósseo. Também foi feita radiografia do tćrax que nade mostrou de ancrmal. O leucograma re velou 6.300 leucócitos por mm3 e 13' de eosinofilos. Eritrograma e proteinas plasnáticas estavam dentro dos limites da normalidade. Uma biopsia da lesão nasal permitiu a identificacão de reação granulomatosa centrada por hifas de um cogumelo, que na cultura foi identificado como Entomophthora coronata. A paciente foi tratada com anfotericina B e dexametazona, com diminuição do edema facial e dos nódulos paranasais, os quais diminuiram de consistência. Estes nódulos todavia nào desapareceram totalmente até um mês após o início do tratamento, quando a paciente abandonou a consulta. Posteriormente, voltov ao Hospital, tendo sido tratada com iodetos, tendo-se obtido excelente resposta. com cura clínica da paciente.

2 Caso - Paciente masculino. preto, com 44 anos, doente há quatro anos. A do ença teve inicio com coriza, sensação de obstrução nasal e aumento do nariz. Fol então submetido a uma intervencāo cirúrgica para remoção de um "polipo nasal". Logo após piorou muito, com aumento do edema da face (região paranasal), com endurecimento local, dor e prurido. Foi visto neste Hospital pela primeira vez um ano após o início dos sintomas. Nesta ocasiāo c exame físico mostrou paciente em bom estado geral, apresentando lesão tumoral ocupando o nariz e a hemiface esquerda, com acentuado aumento de volume do lábio superior, não havendo ulceração cutânea. O exame dos diversos aparelhos não mostrou alteracōes e os exames complementares realizados exames de rotina, incluindo hemograma completol deram resultados essencialmente dentro dos limites da normalidade. Uma biópsia da lesão da face mostrou lesāo granulomatosa contendo hifas nāo septadas, identificadas microscopicamente como Entomcphthoro coronata. Várias tentativas para se cultivar $\checkmark$ fungc foram sempre negativas. O paciente foi submetido a tratamento com a anfotericina $B$, porém demonstrou intolerância à drcga, pelo que o tratamento teve que ser interrompido. Foi também tratado com iodeto de sodio e com várias outras drogas anti-micóticas, porém sempre sem resultados. Esteve em observação por um periodo de três anos, tendo havido acentuado aumento do tamanho do nariz e lábic, além de edema da face. Recentemente o paciente foi submetido à cirurgia plástica para reconstruçãc da face. O tecido rétirado durante esta cirurgia foi examinado histolcgicamente, tendo mostrado grande número de parasitos e extensa reacāo inflamatória e fibrose. Ainda não houve tempo suficiente para se avaliar o resultado final, mas até o presante momento houve melhora acentuada de todo o aspecto do paciente e do seu psiquismo.

\section{ASPECTOS HISTOPATCLOGICOS}

O material para examo histopatológ co constou de pequenos fragmentos de tecido cbtidos por bicpsias em cada caso. A peça cirúrgica do 2 caso forneceu extenso retalho de pele e tecido subcutâneo, com abundante material para estudo. Após fixarão em formol a $10 \%$, inclusão $\mathrm{em} \mathrm{pa-}$ rafina, foram obtidas seccōes, as quais foram coradas pelos seguintes métodos: ho matoxilina e eosina, hematoxilina fostotungstica de Mallory, tricrômico de Masson Weigert Van Gieson, PAS, Gram, prataurotropina de Grocott, reticulina de Gomori e o Ziehl Neelsen. Um pequeno fragmentc de tecido tomado do 2 caso foi fixado imediatamente em álcool absoluto gelado. incluido em parafina segundio a técnica de Saint Marier26, e as secçōes obtidas foram submetidas a tratamento com anti-soros fluoresceinados. Utilizou-se anti-gama globulina humana conjugada à fluoresceina $e$ cbtida comercialmente, sendo que as sec çôes foram ou näo previamente tratadas pelo soro do paciente. Foram examinadas ainda secçôes apenas baixadas em solução salina tamponada. Os cortes foram montados em glicerina tamponała e examinados ac microscópio Zeiss com luz de vapor de mercúrio Osram com filtros barreiras OG-5 e filtros excitaciores BG-12

O material obtido do primeiro caso provavelmente representava infecção recente. Já a doença do segundo paciente teve um decurso mais longo. A cirurgia plás tica a que o paciente foi submetido e que forneceu abundante material para estudo microscópico foi realizada quando a doença já datava de mais de 4 anos. O material estudado permitiu até certo ponto a 
reconstituição da evoluçāo das lesōes causadas pela Entomophthora coronota.

A lesāo mais inicial consistia no aparecimento de granulomas esparsos no der ma profundo e no tecido celular subcutâneo. Quando vistos no material do primeiro caso, os granulomas estavam separados entre si por tecido de aspecto normal, ou pcr difuso infiltrado de predominância Ecsinofila, ou por tecido edemaciajo e com discreto espessamento fibroso. A lesāo granulcmátcsa apresentava ina parte central uin ou mais segmentos de hifa não septada, ramificada, circundada por halo amorfo, eosinófilo, por vezes granular ou radiado. Em torno deste material se dispunham umas duas a cinco camadas de células histiocitárias, com muitos ecsinofilos e linfócitos de permeio. As hifas apareciam largas de paredes finas, com fino conteúdo citoplasmático amorfo eosinófilo, nāo septadas. Impregnavam-se fortemente pelo método de prata-urotropina de Grocott e exibiam positividade para o PAS, para - Gram e o método de Zieh-Nielsen. O material eosinófilo em torno das hifas também era PAS positivo, corava-se em azul como fibrina pelo método da hematoxilina fosfotungstica de Mallory e mostrava certo grau de álcool-ácido resistência, além de fraca argirofilia com o método de Grocott.

No material do segundo caso os granulomas eram encontrados no seib de um denso tecido fibroso, o qual aparecia infiltradc difusamente por muitos linfocitos, plasmocitos e alguns eosinófilos. O infiltrado e a fibrose envolvem também o derma superficial onde não se encontra vam parasitos, mas onde havia muitos vasos telangiectásicos e hipertrofia e hiperplasia de glândulas sebảceas. A epiderme mostrava apenas moderado grau d? atrofia. Quase todo o tecido celular a aiposo subcutâneo estava substituido por fibrose. As lesões aperentemente não envolviam os músculos da face, os quais não estiveram representados nas secções examinadas. Diferente do caso anterior, os granulomas restue caso exibiam sensivel variação de aspecto. Todavia ainda apareciam granulomas com hifas bem preservadas, com brilhante halo eosinófilo e com muitos polimorfo eosinófilos presentes, indicando que a formação de novas lesões com caracteristicas recentes ainda continuava. A cbservação de inumeras secçôes sugeria que a evolução dos granulomas se fazia ccm o aparecimento de muitas células gi gantes, tipo Langhans e tipo corpc estranhc com numero considerável de nucleos. as quais invadiam e fragmentavam a parte central das lesōes. As células gigantes pcdiam ser cbservadas fagocitando restos de hifas juntamente com o seu halo eosinofilc. c cual se tornava progressivamente granular ou grumoso. As alteraçōes degenerativas das hifas se evidenciavam por dilataçoes com desaparecimento do conteúdo citoplasmático, fragmentação e pərda progressiva das afinidades tintoriais.

O material ecsinófilo podia aparecer invadido for células e estas se desintegravan deixando restos nucleares no interior da massa eosinofila ou comunicava-lhe uma tonalidade basófila. O granuloma, mesmo aquele já infiltrado na parte central por células gigantes, podia exibir necrose coliquativa. Às vezes, vários granulomas com necrose central apareciam fusionados. constituindo-se em áreas mais ou menos extensas de necrose de liquefaçào. Estas áreas podiam ser invadidas por leucócitos polimorfonucleares neutrófilos, dando lugar ao aparecimento de micro-abscessos. As lesōes vasculares se limitavam à fibrose adventicial, tumefação endotelial e infil traçãc linfocitária peri-vascular. Alguns linfáticos dilatados foram identificados.

C estudo realizado com técnicas de imunc-fluorescência mostrou aue o material eosinófilo exibia uma auto-fluorescéncia amarelada sob a luz ultra-violeta, mesmo auando a secção havia sofrido apenas lavagem com salina tamponada. Nos cortes tratados com a anti-gama globulina humana fluoresceinada, com ou sem tratamente prévic com o soro do paciente, a auto-fluorescência não se modificou. A flucrescência especifica verde-maçã foi cbservad2 apenas nas paredes das hifas nce ccrtes tratades previamente pelo soro do paciente e em seguida pela anti-gama glcbulina humana fluoresceinada. Assim ficcu evidenciado oue: 1) c soro do paci ente continha anti-corpos circulantes que se fixavam especificamente nas hifas da Entomophtinora coronata; 2) Não foi possival demonstrar a presenca de antigeno ou de gama globulina tanticorpos) no material amorfo em torno das hifas. 


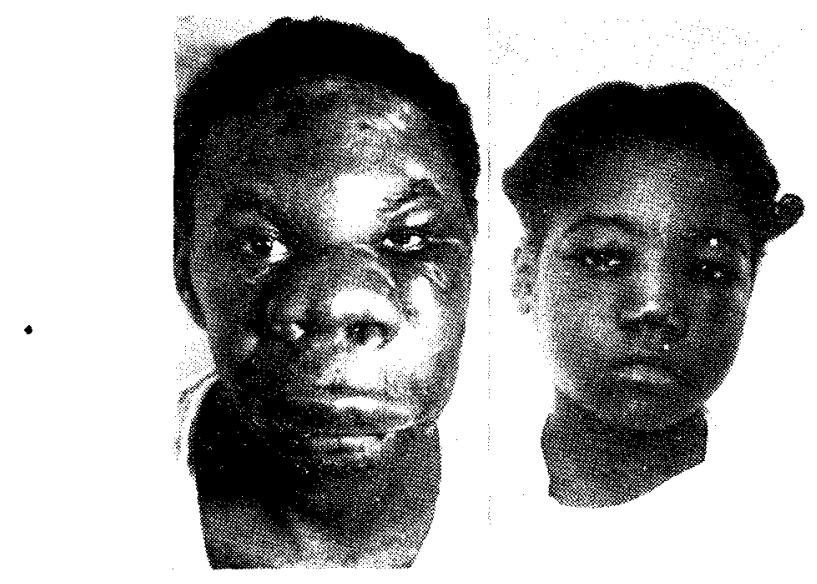

Fis. 1 - Aspecto das alteracōer faciais nos dois pacientes. A menina apresenta edema palpebral e tumefaçáo dá regiăo paranasal. O homem mostra acentuado grau de deformacăo e cdema do nariz e lábio superior.

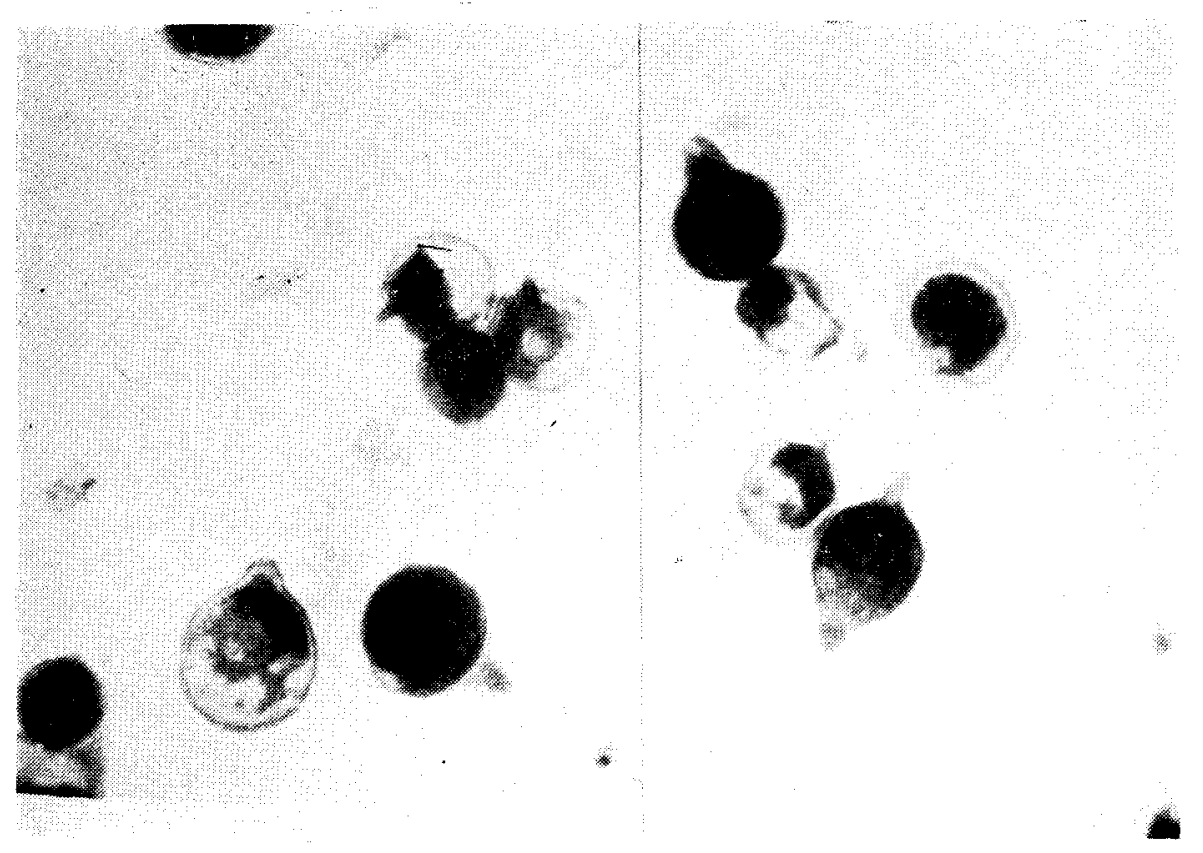

Fig. 2 - E. coronata observada em cultura. Aspecto das conidias $350 \mathrm{x}$ 


\section{COMENTÁRIOS}

a) Generalidades - Os ficomicetos são cogumelos saprofitas muito espalhados em a natureza, alguns grupos parasitando animais inferiores, insetos e plantas. São caracterizados por hifas de grande diâmetro, ramificadas e nāo septadas. Há muito que se sabia que os ficomicetos da familia Mucoraceae podem parasitar o homem, causandc a doença chariada mucormicose. Admite-se que Conheim descreveu bela primeira vez a mucormicose pulmonar em 1865 (18). Desde então numerosos casos foram deseritos, nos auais se identificavam ficomicetos pertencentes aos gêneros $M u$ ccr, Absidio e Rhizopus. Estes parasitos sempre apareceram como "oportunistas", invadindo os tecidos dos individuos já debilitadoe por diabetes com aciolose, por linfcmas, leucemias, por desnutrição, pacientes com imuno-deficiência ou tratados com drogas imunosupressivas. Nestes individuos a doença assume a forma de uma infecção generalizada. Nos tecidos, as hifas nāc septadas exibem uma tendência a invadir vacos sanguineos e induzem ao aparecimentc de um halo de necrose coliquativa com pouca ou nenhuma reaçăo celulai $(11,20,21$ )

Somente em fins da década de 50 é que se tomcu conhecimento que um outro ficomiceto, perteneente ao gènero Basidiobulus - o B. ranarum ou B. meristosporus - era o agente etiológico de uma nova dcenca humana e aue recebeu o nome de ficcmicce subcutanen. Diferente da mu ccrmicosa, a ficcmicose subcutânea é uma acença de evclucăo crónica, ocorrendo geralmente em criancas, sem causas predispcnentes, podcndo curar espontaneamente e se manifestando sob a forma de nódulos subcutaneos. A reaçāo do hospedeiro é um granulcma eosinófilc, exibindo na parte central um tipo peculiar de halo eosinofilo em torno das hifas nāo septadas, as quais nāc mestram tendência a invadir vasos sanguíneos. Esta doença fol descrita inicialmente na Indonesia (15) e logo depois encontrada em alguns paises africanos (14, 16) especialmente na Uganda 18). Peic menos um caso autoctone fol descrito ne. Inglaterra (28). No Brasil só temos co- nhecimento até o presente de um único caso, sem comprovação de cultura, apresentadc por Bandeira \& Oliveira (4).

Quando os nóbulos micóticos foram encontracics envolvendo o nariz e os tecidos paranasais e exibindo um ouadro histológicc típico com hifas não septadas envolvidas por halo eosinófilo, tais casos foram naturalmente considerados como representandc uma localizaçäo nasal da ficomicose subcutânea. Retrospectivamente, podemos considerar como exemplo os descritos for Blaché et al. (6) em 1961, por Straasma et al. (27) em 1962, por Basset \& col. (5) em 1963 e por Peloux \& Foucard (22) em 1964, que observaram casos clínicos típicos, todavia sem comprovação micológica. No entanto, Martinson (17) ao descrever 3 casos em 1363 suspeitou aue o parasito causador desta ficmicose de localidaje nasal devia pertencer a uma espécie ou mesmo a um gênero diferente daquele do Basidiobolus rancrum. Embora sem contar com o exame micológico e tendo verificado um quadro histológico idêntico ao da ficomi ccse subcutânea, ele salientou que c tipo peculiar de manifestação clínica estava a indicar algo mais cue uma simples varianto da doenca causada pelo $B$. ranarum. Utilizou para os seus casos a designaçāo de rinoficomicose, nome impróprio poraue já atilizado anteriormente para designar uma mucormicose de Iocalização nasal (11) Foi somente em 1965 que a entomoftorosi nasil foi definitivamente reconhecida como ncva entidade clinica causada por Entomophthora coronata, um ficomiceto que em 1961 havia sido identificado como o agente causador de granulcmas nasais en cavalos do Texas, E.U.A. (13). Foram Bras et al. (7) na Jamaica e Renoirte et al. (23) no Congo ex-francês quie descreveram simuitânea $e$ independentemente, um cas s cada, exemplificando a infecção humana. A partir dai novas observaçōes desta entidade vieram a ser feitas no Brasil 121 no. Colombia $(24)$ e principalmente na $\mathrm{Ni}$ geria $(9,10,18,19,29)$

Todos os casos até aqui descritos, 28 dos quais revistos por Clark (9), mostram entidade clínico-patológica bem definida Excluindo-se o caso de Ridley \& Wise (25) de uma ficomicose generalizada e com ca-

O fungo foi também identificado em muar no Brasil (Johnston, M.J. et al "Ficomiccse em ruar. 1so. lamento da entchophthora coronata". - Arq. Inst. Biol. 34. 51-58. 1967. 
racteristicas histologicas semelhantes às da entomoftorose, porém sem comprovaçāo micclogica, todos os outros cascs descritos mostraram lesōes limitadas à face (regiāo nasa!!

Os pacientes, quase todos de raça negra, apresentam uma lesão inicialmente lccalizada na mucosa nasal, com tumefacāo, corrimento e obstrução nasal. Formam-se depcis massas nodulares, mal delimitadas, elásticas, projetando-se no interior das iossas nasais, extendendo-se aos seics paranasais e ao naso-faringe. Massas irregulares aparecem nos tecidos paranasais, na região frontal e no lábio supericr. os tecidos envolvidos mostram um edema curc, com caracteristicas de linfoedema e vão sofrendo progressiva transformacāo fibrcsa. Ae lesōes acabam por causar profunda deformaçāc da face. A radiografia da face ajuda a comprovar a extensão dos seios paranasais e o nāo comprometimento ósseo. O estado geral do paciente não $\dot{\epsilon}$ afetado e não há evidências que as lesós determinadas pelo fungo possam ser enccntradas fora dos tecidos iderma profundo e tecido celular subcutâneos da regiãc naso-facial.

b) Histopatologia -... O quadro histopatológico da entomoftorose nasal é idêntico ao da ficomicose subcutânea. Todavia todas as culturas positivas para as lesōes da face sempre demonstraram a Entomophthora coronata, a aual nunca foi encontrada nas lesōes subcutâneas. Estas ilitimas sempre revelaram o Basidicbolus. Assim sendo, o quadro histopatologico que já descrevemos em detalhes pode ser diagnosticado com segurança como entomoftorcse por $E$. coronata, se o material foi retirado da lesāo nasal. Isto todavia nāo indica que a cultura do fungo deva ser negligenciada. A cultura continua a ser, também nesta doença, o meic indispensável para um diagnóstico absoluto.

Muita discussão aparece na literatura acerca da natureza do envólucro eosinófilo em torno das hifas dos ficomicetos. Este material foi comparado àquele que aparece em casos de esporotricose, actinomicose, blastomicose e várias outras micosas. 18) Tarbém foi considerado semelhante ao material aue aparece $\mathrm{em}$ torno da larva migrans visceral (27), em torno de filsirias (29) e de ovos do $S$. mansoni (fe- nômeno de Hoeppli) (29). Também tem sido sugerido que o material eosinófilo é formado por fibrina (28), que não contém fibrina (16), aue contém material derivado das hifas (29), que é um complexo de materiais do hospedeiro e do fungo 128 , e que representa uma reação antígeno-anticorpe 18,291 . Os nossos estudos indicam que o material eosinofilo contém grande quantidade de fibrina, em vista de suas características histológjcas apresentadas acima. C exame sob luz ultra-violeta demcnstrcu uma autofluorescência amarelada tal como costumam apresentar os dapósitos de lipofuscina, um pigmento que já foi demonstrado no halo eosinófilo da ficcmiccse histoquimicamente (29). Quanto à presença de antigeno ou de anticorpos, os nossos resultados foram inteiramente negativos. Isto sugere que não há qualquer semelhança com o fenomeno de Hoeppli da esquistossomose, cnde tanto antigeno como anticorpos já foram demonstrados imunocitoquimicamente $(3)$.

c) Imunopatolagia - Nossos Estudso sobre a imunopatologia da entomoftorose nasal sāo muito preliminares, mas são os primeiros a serem feitos nesta doença. A técnica da imunofluorescência empregada permitiu verificar a presenca de anticorpos circulantes no soro do paciente. Estes anticorpos poderão vir a ser identificados no futuro com técnicas sorológicas mais simples fixaçāo do complemento, testes de fluoculaçă, hemoaglutinação, etc.l com finalidades diagnósticas e para accmpanhamentc clínico ou criterio de cura. A presença de gama globulina (anticorpos? nāo poude ser comprovada em nenhuma estrutura do granuloma. A técnica empregada de inclusão em parafina talvez não tenha sidc adequada para revelar globulina nos tecidos, muito embora outros 126 , e nós mesmos 11; já tenhamos conseguido ta! demonstracão com esta técnica.

A correlacão dos aspectos histológicos com o estado imunitario do paciente merece ser melhor investigada. A presença de muitos eosinólilos, de plasmćcitos, de necrose fibrinóide e de necrose coliquativa. com formação de muitas células gigantes. com infiltrados linfocitários perivasculares e com a evolução das lesōes para densa fibrose estāo a sugerìr a participaçāo de fatores de hipersensibilidade na patogenia da entomoftorose nasal. 


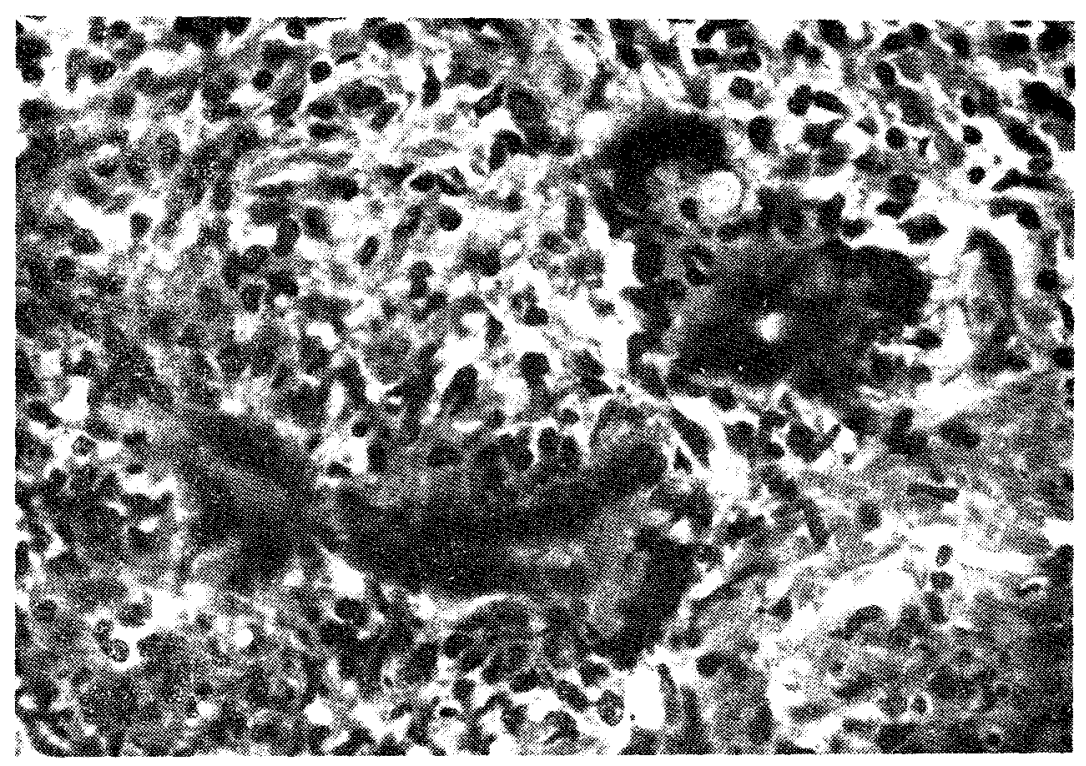

Fing. 3 - Hifas da $E$, coronata en cortes transversais clicundedas por material eosinófilo e reação sranulomatosa. Enematoxilina e eosina. $450 \mathrm{X}$

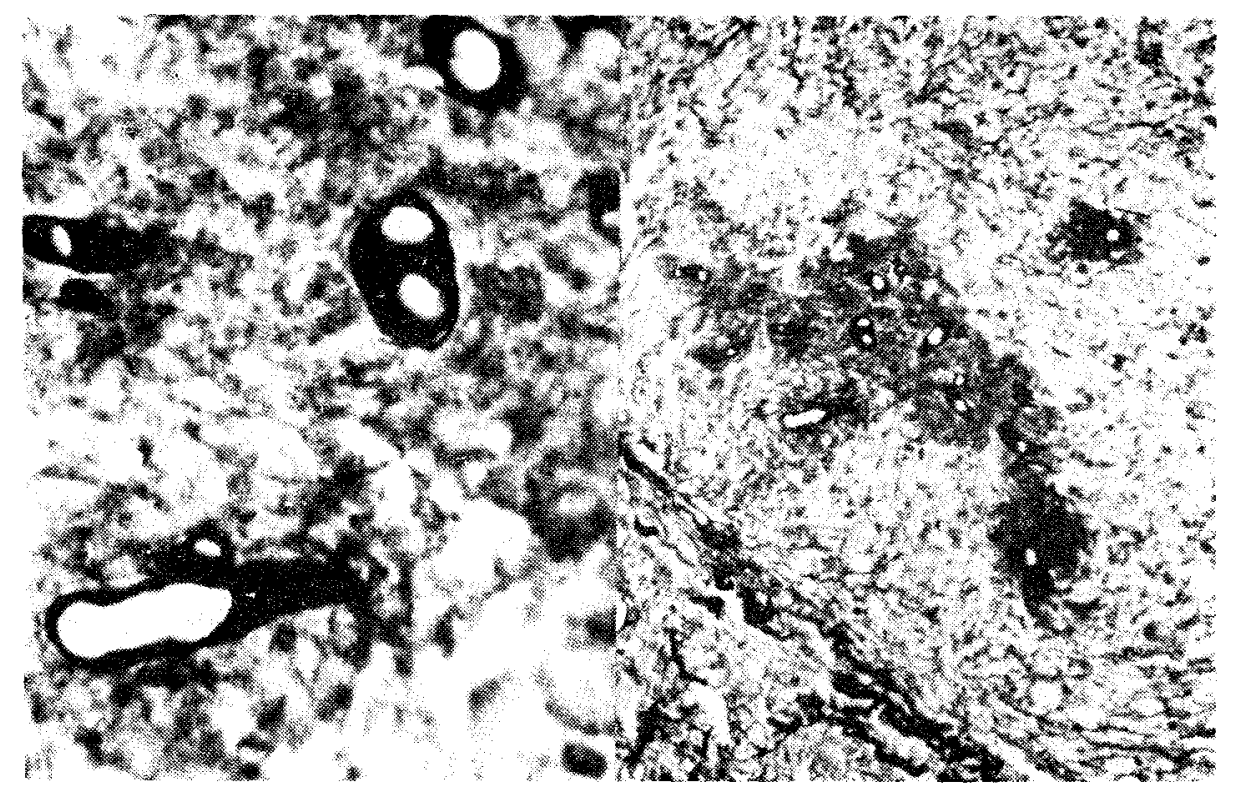

Fig. 4 - Intensa imoregnaço arôntica das hifas ae E, coronatu em cortes corados pelo método da prata urotropina de Grocott. Notar lambém ligeira argirofilia no ma. terial amorfo em torno das hifas. $150 \mathrm{X}$ e $450 \mathrm{X}$. 


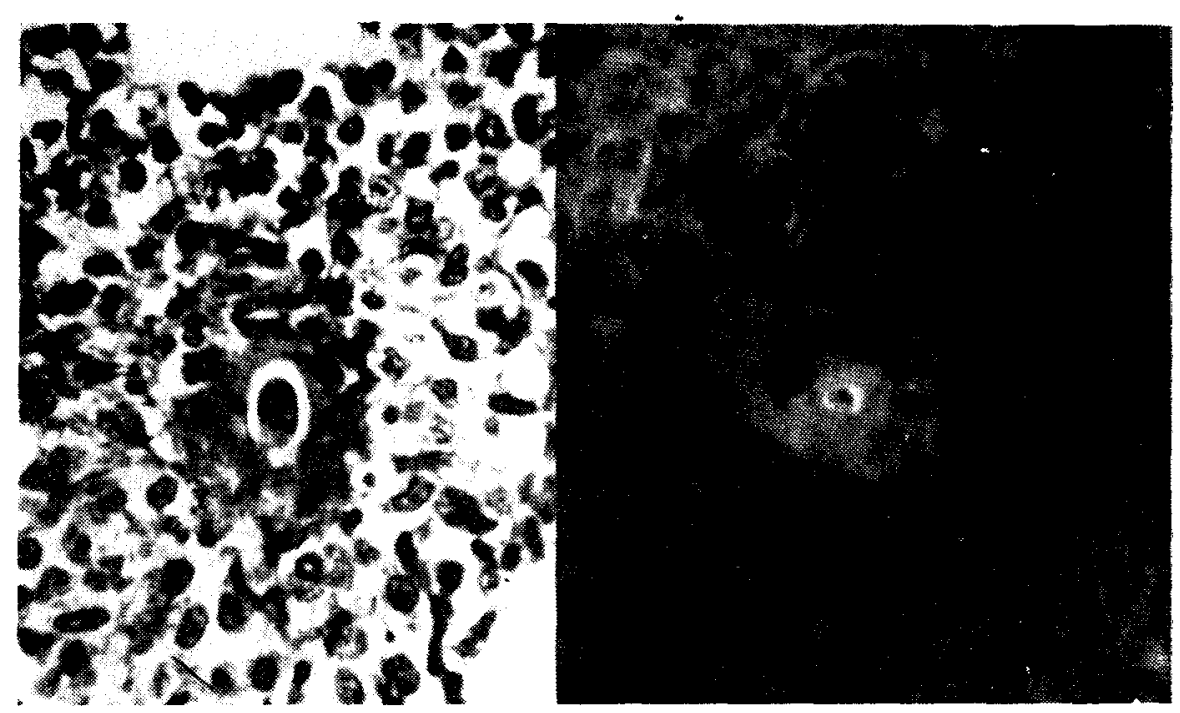

Fis. 5 - Lesão em torno de hifa da $E$, corcnata, vendo-se bem o envolucro eosinofilo. A esquerda, secçăo ccrada pelo método do PAS. A direita, microscopia de îuoresên. cia com corte tratado pelo soro do paciente e em seguicia por anti-gama glcbulina humana fluorasceinada A fluorescencia da hifa revela a presenca de anticcryos do sôro do paciente. A luorescência en tomo é devida a lima auto-fincrescência do envólucro eocinófile. $150 \mathrm{X}$.

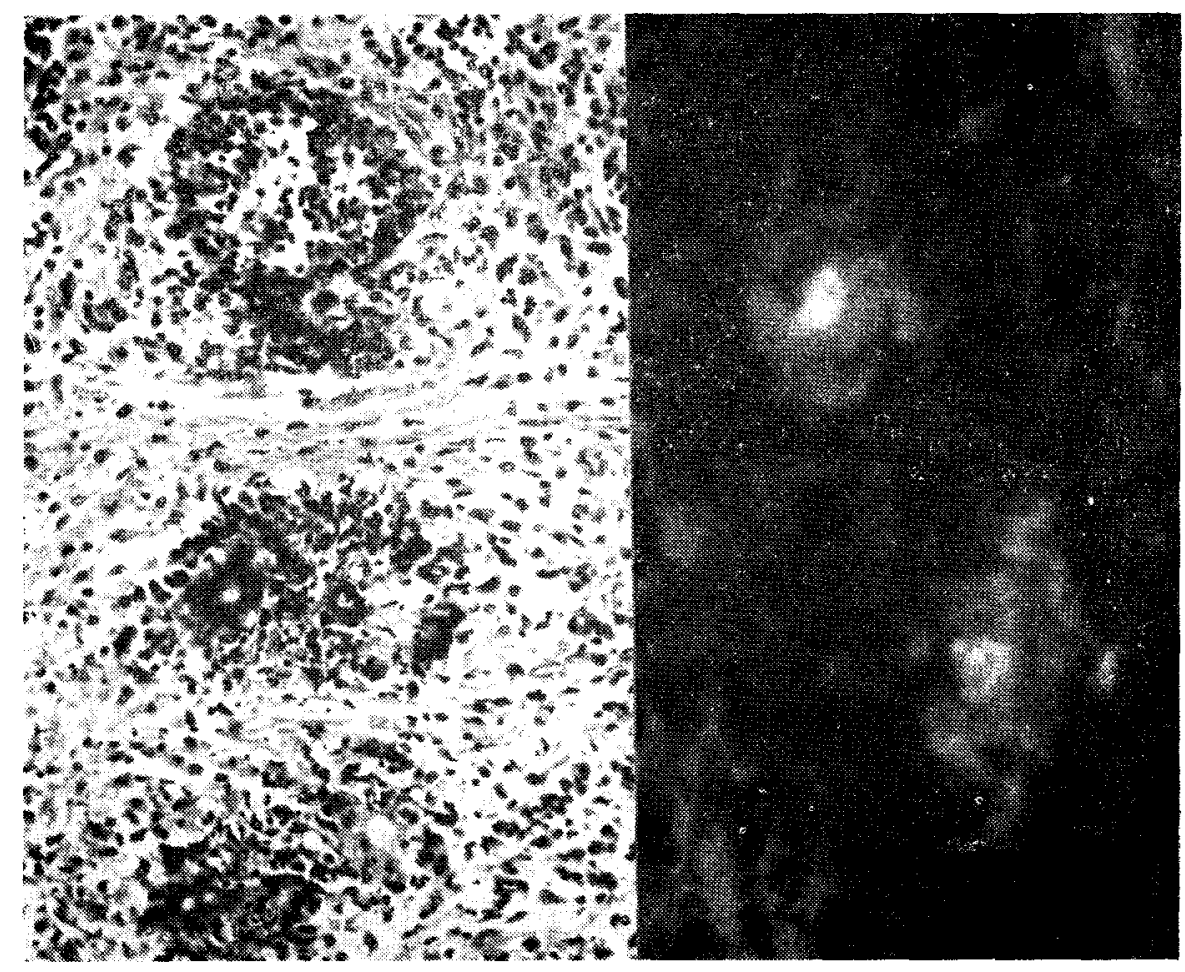

Fig. 6-Granulomas em torno de hifas de E. coronata sofrendo amolecimento central e invasão de leucócitos (Métcdo do PAS). A direita, outros aspectos de fluorescência especifica das hifas em material tratajo pelo sôro do paciente seguido da anti-gama globulina humana fluoresceinada. $150 \mathrm{X}$. 
d) Micologia - O fungo E. coronata, tão facilmente cultivado no primeiro caso, nãc o póde ser no outro caso, mesmo após insistentes tentativas. Casos semelhantes estão citados na literatura $(6,27)$. Martinson (18) sugere que muitas vezes as hifas estão mortas no interior dos granulomas, daí a negativiàade das culturas.

De modo geral, as cuituras iniciais em meio Sabouraud glicosadc se desenvolvem a partir do 4 dia, tanto à temperatura ambiente como a $37^{\circ} \mathrm{C}$. As repicagens se desenvolvem em 48 hcras à tempsratura ambiente. As colonias, de inicio, săo planas, lisas transparentes $c$ depois tomam um aspecto membranosc, fulverulento, de cor branco amarelada, com desenvolvimento superficial, forrando as paredes do tubo por material pulveruiento constituido por esporos assexuados, alguns en inicio de germinação. Com o envalhecimento as culturas mostram uma ccloraçãc amarelada mais intensa, podendo chegar ao marron e com maior espalhamento periférico. Microscopicamente, as hifas aparecem ramificadas, nāo septadas, irregulares, com diâmetro variando entre 5 a 18 micra. As paredes das hifas sâo espéssas e o citoplasma granuloso, freqüentemente contendo gcticulas arredondadas ou ovóides. As hifas dãc origem aos conidioforos aue prccuzem as conidias. Estas ultimas sāo redonalas e medem cerca de 40 micra de diametro quando maduras. Quando se destacam apresentan uma saliencia na sua porção basilar. Os conidias são também caracterizadas pela presença de apèndices capilariformes, que se irradiam de sua superficie, dai c nome "coronata"

e) Fatclcgia Experimental -... Até o Fresente momento a entomoftorose nasal nãc foi reproduzida experimentalmente. Com material de cultura obtido do primeirc casc já foram feitas tentativas (2) para ce infectar camundongos, ratos, cobaias, ccelhos e hamsters através de injeçōes intravenosas, intramusculares e subcutâneas com resultados sempre negativos. Em ratos, c material de cultura foi injetado ao mesmc tempo em oue se fizeram injeções diárias de cortisona $10.5 \mathrm{mg} / 20 \mathrm{~g}$ peso corporals durante 30 dias. Ainda assim, não se conseguiu obta* prcliferação do fungo nos tecidos. f) Tratamento - A julgar pelos casos publicados na literatura, o tratamento desta micose ainda é um problema para ser resclvido. O nosso primeiro caso respondeu bem ao tratamento com anfotericina $\mathbf{B}$. Depois de um período de interrupção do tratamento veio a ser tratada com iodetos çuando aparentemente se curou; já o paciente do segundo caso mostrou intolerância a todos os tratamentos medicamentoscs a que foi submetido. Depois, devido à grande deformação da face, indicou-se ume cirurgia plástica que parece ter daso bons resultados. Todavia o uso de tal terapêtica cirúrgica ainda necessita ser melhor avaliado. Os molhores resultados têm side conseguidos com iodetos. Martinson (18) recomenda a dose de $3 \mathrm{~g}$ diárias para aqultos e diz que as lesōes desaparecem em 3 a 6 meses, mas rue o tratamento deve ser continuado por mais 3 meses. A anfotericina $B$ tem também dado bons resultados, mas é uma droga muito tóxica $e$ deve ficar para os casos que não respondem acs icdetcs, ou para ser usada em pericdos curtcs de tratamento nos intervalcs de outras drogas. Martinson (18) acha que a adicāo de uma sulfa pode ser útil ao tratamento

g) Epiatmiciogia -... Entomophthora coronata existe no scio onde há plantas em decomposição e pode ser também encontradc parasitando insetos. Estudando amestras de solo colhidas em diferentes meses dc ano, Clark (9) conseguiu isolar em cultura a Entcinsohthora coronata. sendo que c maior numero de colonias se desenvolveu quando a amcstras eram coihidas nos meses chuvcsos. Fevendo os as. pectos epidemiológicos, aduela Autora assinala que tcáos os casce descrites na ri. geria, em númcro de $i 4$, representavam is.dividuos aue residiam cm regioes de fiorestas tropicais, baixas e chuvosas, e $\mathrm{na}$ maicria envolvidos ern trabalho de agricultura. Apesar da elevada incidência do parasito no solo das zonas tropicais úmidas, os casos humanos da doença são raros. Não é provável que esta raridade reflita apenas uma falta de reconhecimento da doença pelcs médicc. A razão deve estar na baixa patogenicidaje do fungo. A infecção do hcmem se dá provavelmente pela muccsa nasal, por inalacão de esporos ou ela inoculação dos mesmos através de pequenos traumatismos. 


\section{SUMMARY}

Two cases of rhino-entomophthoramycosis. a new human disease caused by a phycomycete Entomophthora coronata, are presented. The patients, a gir? and a man aged 8 an 44 years respectively, showed a lccalized disease involving the nose and paranasal areas. The parasite was easily isolated from the first patient but every attempt to cultivate the organisms from the second resulted unsuccessful. Histologically, there were granulcmatous formations, fibrosis and Edema, around nonseptated hyphae, which appeared surrcunded by an amorphous eosinophylic material. Antibodies binding specifically to the hyphae were demonstrated in one patient's serum. The eosinophylic material around the hyphae contained fibrin and a yellowish autofluorescent component. probably ilpofuscin. but neither antibodies. nor antigens could be demonstrated in it.

The presentation of the cases is followed by a general review on rhinountomonhtroromycosis. since that diseose may be fo importance to aoctors working in Brasil, a trcpical country.

\section{REFERÊNCIAS BIBLIOGRÁFICAS}

ANDRADE, Z. A. \& ANDRADE, S. G -.- Estudo imunocitoquimico da doença de Chagas experimental. Rev Inst. Med. Trop. São Paulo, 11: 4447. 1969.

2 - ANDRADE, Z. A.: PAULA, L. A.: SHERLOK, I. A. \& CHEEVER, A. W. - Nasal granuloma caused by Entomophthord coronata. Amer. J. Trop. Med. \& Hyg. 16: 31-33, 1967

3 -.- ANDRADE, Z. R., PARONETTC, F. \& POPPER, H. - Immunocy tochemical studies in schistosomiasis. Amer. J Path. 39: 589-598, 1961

4 - BANDEIRA, V. \& OLIVEIRA, S. .Ficomicose tegumentar. Apresentacão ao VT Congresso Brasileiro de Patologia, Salvador. Bahia, julho 1966 .

5 -... BASSET. A.; CAMAIN, R. \& LARIVIERE. M - Trois cas sénégalais de Phycomycose. Bull. Soc. Path. Exot. 56: 108-112, 1963.

6 -.. BLACHE, R., DESTOMBES, P. \& NAZIMOFF. O. - Nouvelles mycoses sous-cutanées au Sud-Mameroun. Bull. Soc. Path. Exot. 54: 56-63, 1981.

7 BRAS, G.; GORDON, C.C., EMMONS C. W. PRENDEGAST, K. M. \& SUGAR, M - A case of phyccmycosis observed in Jamaica; infection with Entomophthorn coronate Amer. J. Trop. Med. \& Hyg. 14: 141-145, 1065.

8 - BURKITT, D. P., WILSON, A. M. M. \& JELLIFFE, D. B. - Subcutaneous Phycomycosis: a review of 3 cases seen in Uganda. Brit. Med. J. 1: $1669-1672,1964$
9 CLARK, B. M. - The epidemiclogy of phycomécosis. In Systemic Mycoses, A Ciba Symposium, J. A. Churchill Ltd., London pp. 179-192, 1968.

10 - COCKSHOTT, W. P.; CLARK, B. M \& MARTINSON, F. D. - Upper respiratory infection due to Entomoththora coronata. Rhino-entomophthoromycosis. Radiology 90: 10161019,1968

11 - DWYER, G. K. \& CHANGUS, G. W - Rhino-mucormycosis resulting in fatal cerebral mucormycosis. Arch. Otolaryng. 67: 619-623, 1958.

12 - EDINGTON. G. M. - Phycomycosi in Ibadan, Western Nigeria. Two postmortem reports. Trans. Roy. Soc Trcp. Med. \& Hyg. 58: 242-245, 1964

13 -.. EMMONS, C. W. \& BRIDGES. C. H Entomophthora coronata the etiologic agent of a phycomycosis of horses. Mycologia 53: 307-312, 1561

14 JELLIFFE. D. B. BURKITT, D. P. O'CONOR. G. T. \& BEAVER, P. C. ... Subcutaneous phycomycosis in an East African child. J. Pediat. 59 $124-127,1961$.

15 -... JOE, L. K. \& TJOEI ENG, N. J.Subcutaneous phycomycosis: a new disease found in Indonesia. New York Acad. Sci. 89: 4-16, 1960.

16 -.. LYNCH, J, B. \& HUSBAND, A. D. Subcutaneous phycomycosis. J. Clin Path. 15: 126-132, 1962

17 - MARTINSON, F. D. - Rhinophycomycosis. J. Laryngol. \& Otol. 77: 691-705. 1963. 
18 - MARTINSON, F. D. - Chronic phycomycosis of the upper respiratory tract. Amer. J. trop. Med. \& Hyg. 20: $449-455,1971$

19 - MARTINSON, F. D. \& CLARK, B. M. - Rhinophycomycosis entomophthorae in Nigeria. Amer. J. trop. Med. \& Hyg. 16: 40-47, 1967.

20 - NEAME, F \& RAYNER, D. - MUcormycosis. A report of twenty-two cases. Arch. Path. 70: 261-268, 1960

21 - PARKHURST, G. F. \& VLAHIDES. G. D. - Fatal opportunistic fungal discase. J. Amer. Med. Assoc. 202: 27 S -231 . $196 \%$

22 - PELOUX, Y \& FOUCARD, H. - La phycomycose. Med trop. (Marseille) 24: $447-452,1964$.

23 - RENOIRTE, R.; VANDEPITTE, J.: GATTI F. \& WERTH, R. - Phycomyccse nasofaciale (Rhinophycomycose due a Entomophthora coronata. Bull. Soc. Path. Exot. 58: 847-862. 1965.
24 - RESTREPO, A.: GREER, D. L.: ROBLEDO, M.; DIAZ, C.; JOPEZ, R. \& BRAVC, C. -- Subcutaneous phycomycosis: report of the first case observed in Colombia, South America. Amer. J. trop. Mied. \& Hyg. 16: $34-39,1967$.

25 - RIDLEY, D. S. \& WISE, M. - Unusual disseminated infection with a phycomycete. 90: 675-679, 1965.

26 - SAINTE-MARIE, G. - A parafin embedding technique for studies employing immuno-flucrescence. $J$. Histcchem. \& Cytorhem. 10: 250$25 \mathrm{C} 1361$.

27 - STRAATSMA, B. R.; ZIMMERNAN. L. E. \& GRASS, J. D. - Phycomycosis. A clinicopatholcgie study of fifty one cases. Lab. Invest. 11: 963-985. 1862

28 -.. SYMMERS, W. ST. C. - Fungi in human and animal disease Proc. Soc. Med. 57: 405-411, 1964

25 - WILliams. A. O. - Pathology of phycomycosis due to Entomophthora and Basidioboius species. Arch. Path. 87: 13-30, 1969 . 